\title{
Efeito do Período Experimental sobre a Digestão Parcial e Total em Bovinos Alimentados com Dois Níveis de Volumosos ${ }^{1}$
}

\author{
Kátia Cylene Guimarães ${ }^{2}$, Antonio Ferriani Branco ${ }^{3^{*}}$, Lúcia Maria Zeoula ${ }^{3^{\star}}$, Ivanor Nunes do Prado ${ }^{3^{*}}$, \\ Gisele Fernanda Mouro², Fábio Jose Maia ${ }^{4}$, Luís Paulo Rigolon ${ }^{3}$
}

\begin{abstract}
RESUMO - Os objetivos deste trabalho foram avaliar os efeitos de dois períodos experimentais e dois níveis de volumosos na dieta sobre a digestibilidade total e parcial da matéria seca (MS), matéria orgânica (MO), proteína bruta (PB), fibra em detergente ácido (FDA), fibra em detergente neutro (FDN), energia bruta (EB) e amido. Foram utilizados quatro novilhos da raça Holandês Preto e Branco, com dois anos de idade e $340 \mathrm{~kg}$ de peso vivo e canulados no rúmen e duodeno. O delineamento experimental utilizado foi o quadrado latino $4 \times 4$, em que os animais receberam quatro tratamentos, que consistiram de dois níveis de volumosos (30 e $70 \%)$ e dois períodos experimentais (14 e 21 dias). Houve efeito significativo do nível de volumoso sobre a digestibilidade ruminal de FDA e FDN, a digestibilidade intestinal e total da MS, MO, PB e amido e a digestibilidade total da EB. Não houve efeito do período experimental sobre os coeficientes de digestibilidade dos nutrientes avaliados. Conclui-se que a utilização de período experimental de 14 dias, em experimentos de digestão, é viável, quando se utiliza feno como fonte de volumoso.
\end{abstract}

Palavras-chave: digestibilidade, nível de volumoso, período experimental

\section{Effect of Experimental Periods on the Parcial and Total Digestion in Cattle Fed Two Levels of Forage}

\begin{abstract}
The objective of this research was to evaluate the effects of two experimental periods and two forage levels in the diet on the total and parcial apparent digestibility of dry matter (DM), organic matter (OM), crude protein (CP), acid detergent fiber (ADF), neutral detergent fiber (NDF), gross energy (GE) and starch. Four Holstein steers, averaging two years old and $340 \mathrm{~kg}$ of body weight, ruminally and duodenally cannulated, were used. The experimental design was a $4 \mathrm{x} 4$ latin square and the animals received four treatments as following: two forage levels (30 and 70\%) and two experimental periods (14 and 21 days). There was effect of forage level on intestinal and total digestibility of DM, OM, CP and starch and on total digestibility of GE. There was effect of forage level on ruminal digestibility of ADF and NDF. There was no effect of experimental periods on the digestibility coefficients of the nutrients. It was concluded that 14 days experimental period is practible when hay is used.
\end{abstract}

Key Words: digestibility, experimental period, forage level

\section{Introdução}

A digestão em ruminantes é o resultado de uma seqüência de processos que ocorrem em diferentes segmentos do trato digestivo e incluem a fermentação dos componentes dietéticos pelos microrganismos do rúmen-retículo, a hidrólise ácida e a degradação enzimática no abomaso e intestino delgado do animal hospedeiro e a fermentação secundária no intestino grosso (SIGNORETTI et al., 1999).

Estudos de digestão usando ruminantes fistulados com cânulas no abomaso ou no intestino são usados para estimar o desaparecimento e o fluxo de nutrientes do rúmen e, para que esses estudos sejam de valor, é preciso que os dados sejam acurados e precisos (TITGEMEYER, 1997).

Segundo MERCHEN (1988), o objetivo de um experimento de digestão é medir, acuradamente, a quantidade de alimento consumido e de fezes excretadas em determinado período de tempo, podendo, assim, determinar o coeficiente de digestibilidade dos nutrientes que desaparecem durante a passagem através do trato digestivo. As medidas de digestibilidade, por sua vez, contribuem, significativamente, para o desenvolvimento de sistemas usados para descrever e avaliar o potencial nutritivo dos alimentos (VAN SOEST, 1994).

Os estudos de digestão parcial de diferentes

\footnotetext{
1 Trabalho apresentado como parte da Dissertação de Mestrado do primeiro autor.

2 Estudante da Pós graduação em Zootecnia da UEM- AV. Colombo, 5790 CEP 87020-900, Maringá PR.

3 Professor do Departamento de Zootecnia da UEM - AV. Colombo, 5790 CEP 87020-900, Maringá PR. E.mail: afbranco@uem.br

4 Aluno da Graduação em Zootecnia da UEM - AV. Colombo, 5790 CEP 87020-900, Maringá PR.

* Bolsista Pesquisador do CNPq.
} 
dietas são importantes, porque permitem quantificar a utilização dos nutrientes nos diferentes compartimentos do trato digestivo, facilitando a avaliação das diferenças existentes entre as mesmas.

A determinação da digestibilidade dos nutrientes, em várias partes do trato digestivo, requer a coleta de amostras representativas da digesta nos locais envolvidos. THEURER et al. (1981) relataram que a canulação apropriada não influencia a taxa de fluxo da digesta ao longo do trato digestivo, entretanto, a alimentação, a ruminação e a frequiência do período de coleta podem afetar a taxa de fluxo. O procedimento de utilização de cânulas em diferentes segmentos do trato digestivo de ruminantes tem se tornado comum para a coleta de digesta.

Segundo THEURER et al. (1981), várias amostras são usualmente coletadas através de cada cânula (e compostas para análises), tanto por procedimentos de coleta intensiva em um período curto de tempo ( 1 a 2 dias), ou por coletas de longo período ( 6 a 12 dias), com intervalos menos freqüentes. O período de coleta das amostras deve ter duração suficiente para reduzir ao máximo os erros resultantes da excreção irregular das fezes e da variação diária no comportamento dos animais (EZEQUIEL et al., 1995).

Em experimentos convencionais de digestão, os animais experimentais são alimentados com dietas testes por um período preliminar (período de adaptação) de cerca de duas semanas, para assegurar que resíduos dos alimentos consumidos, antes da fase experimental, tenham sido eliminados do trato digestivo. Níveis pré-determinados de ingestão são estabelecidos durante o período preliminar, para evitar flutuações drásticas na excreção (MERCHEN, 1988).

Um fator importante a ser considerado nos experimentos de digestão é a relação concentrado:volumoso, pois estudos realizados por autores como RODRIGUEZ et al. (1997) e OSPINA e PRATES (1998) indicaram variaçãonos coeficientes de digestibilidade dos nutrientes, em função do nível de volumoso.

Com a finalidade de padronizar estes experimentos, procurando, assim, conseguir resultados comparáveis e conclusivos, surge a necessidade de pesquisas que verifiquem as possíveis semelhanças e/ou diferenças que existem nas diferentes metodologias.

O objetivo desta pesquisa foi verificar o efeito de dois períodos experimentais e dois níveis de volumosos sobre a digestibilidade aparente total e parcial da matéria seca (MS), matéria orgânica (MO), proteína bruta (PB), fibra em detergente ácido (FDA), fibra em detergente neutro (FDN), energia bruta (EB) e amido.

\section{Material e Métodos}

O experimento foi realizado no setor de Bovinocultura de Corte da Fazenda Experimental de Iguatemi, pertencente à Universidade Estadual de Maringá, localizada no distrito de Iguatemi, no período de dezembro de 1998 a abril de 1999.

Os animais permaneceram em baias individuais com $10 \mathrm{~m}^{2}$ de área útil, com piso concretado e 50\% da área coberta. As baias eram providas de comedouro individual coberto e bebedouro coletivo para cada duas baias.

Foram utilizados quatro novilhos, Holandês preto e branco, com dois anos de idade e $340 \mathrm{~kg}$ de peso vivo. Os animais eram providos de cânulas ruminal e duodenal (do tipo T-simples).

Os animais foram alimentados duas vezes ao dia, pela manhã $(8 \mathrm{~h})$ e à tarde $(16 \mathrm{~h})$, receberam água à vontade e foi mantido um controle higiênico/sanitário rigoroso das instalações. As baias foram lavadas duas vezes ao dia e os bebedouros, semanalmente, assegurando, assim, o fornecimento de água de boa qualidade. Os animais foram pesados no início de cada período experimental, com o objetivo de ajustar o fornecimento de matéria seca.

Os períodos experimentais foram de 14 ou 21 dias, com três dias de coleta de amostras (digesta e fezes), no final de cada período.

As dietas (Tabela 1) foram calculadas para atender 1,3 vezes a exigência de energia de mantença e os tratamentos foram avaliados em esquema fatorial $2 \times 2$, sendo dois níveis de volumosos (30 e 70\%) e dois períodos experimentais ( 14 e 21 dias).

A concentração estimada de energia metabolizável e proteína bruta das rações foi: $\mathrm{AV}=2,23 \mathrm{Mcal}$ de $\mathrm{EM} / \mathrm{kg}$ de $\mathrm{MS}$ e $12,5 \%$ de $\mathrm{PB}$ e BV $=2,58 \mathrm{Mcal}$ de $\mathrm{EM} / \mathrm{kg}$ de $\mathrm{MS}$ e $13,3 \%$ de PB. Os ingredientes das rações foram misturados em misturador vertical (PEREIRA ${ }^{\circledR}$ ) por 15 minutos, com exceção do feno, que foi triturado em triturador de forragem (NOGUEIRA $^{\circledR}$ ) e fornecido diretamente no cocho. O processamento do feno foi realizado com o objetivo de evitar perdas e facilitar o arraçoamento. Foram fornecidos $50 \mathrm{~g} /$ dia de sal mineral no período da manhã.

O óxido de cromo foi utilizado como indicador para determinar o fluxo da digesta, sendo o mesmo colocado por meio da cânula diretamente no rúmen, em duas doses diárias de $5,0 \mathrm{~g}$, durante todo o período experimental. O indicador foi fornecido nos horários de alimentação.

Para determinar a digestibilidade total e parcial 
890

Rev. bras. zootec.

Tabela 1 - Proporção dos ingredientes usados nas dietas (\% MS)

Table 1 - Ingredient proportion used in the diets (\% DM)

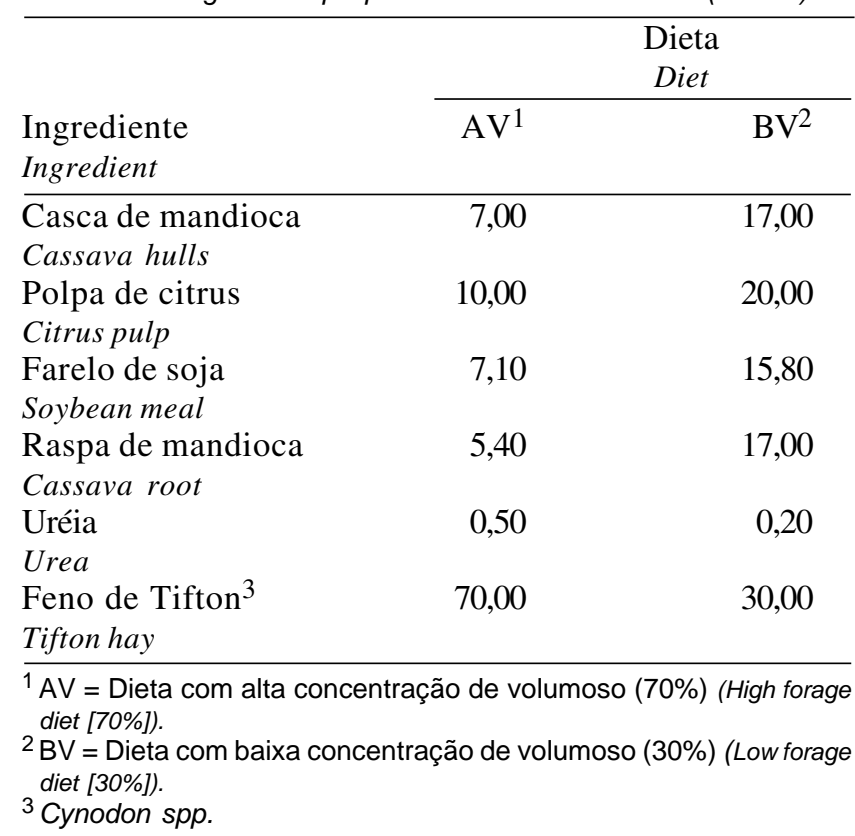

da MS, MO, FDN, FDA, PB e amido foram coletadas amostras da digesta duodenal $(200 \mathrm{~mL})$ e fezes $(50 \mathrm{~g})$. As amostras de digesta e fezes foram acondicionadas em sacos plásticos, devidamente etiquetados e congeladas para posteriores processamento e análises. As amostras de digesta duodenal e de fezes foram coletadas por um período total de três dias, em intervalos de 6 horas, com um incremento de 2 horas de um dia para o outro, totalizando 12 amostras de digesta duodenal e 12 de fezes por animal e tratamento.

As amostras de digesta duodenal e de fezes foram secas em estufa com circulação forçada de ar (MA035-MARCONE ${ }^{\circledR}$ ) a $55^{\circ} \mathrm{C}$ por 72 horas, moídas, individualmente, em moínhos de faca $\left(\right.$ MARCONE $^{\circledR}$ ), utilizando peneira com crivo de $1 \mathrm{~mm}$, e misturadas em quantidades iguais, com base no peso seco, para formar amostras compostas de digesta e fezes por animal e tratamento.

As sobras de alimento no comedouro foram recolhidas diariamente, pesadas e amostradas, sendo, então, congeladas para posterior análise. Após, sofreram o procedimento descrito anteriormente para o preparo das amostras de digesta duodenal e de fezes. As amostras dos concentrados experimentais foram realizadas, semanalmente, e misturadas em amostras compostas, para todo o período experimental e o feno foi amostrado, diariamente, formando, posteriormente, amostras compostas, para cada período experimental.
As amostras dos alimentos utilizados nas dietas experimentais, das sobras no cocho, de digesta duodenal e de fezes foram analisadas para teores de MS, MO, PB, FDN e de FDA, utilizando-se os métodos descritos por SILVA (1990). O teor de amido das amostras de alimento, sobras, digesta duodenal e fezes foi analisado pelo método de Poore et al. (1989) adaptado por PEREIRA e ROSSI (1995). A concentração de cromo $(\mathrm{Cr})$ nas amostras de digesta duodenal e de fezes foi determinada por espectrofotometria de absorção atômica, conforme técnica descrita por WILLIANS et al. (1962).

A energia bruta (EB) das amostras de alimentos, sobras, digesta e fezes foi determinada em bomba calorimétrica $\left(1281 \mathrm{PARR}^{\circledR}\right)$, a partir da qual se calcularam energia digestível(ED), energia metabolizável (EM), energia líquida de mantença (ELm) e energia líquida de ganho (ELg). A ED foi calculada a partir do coeficiente de digestibilidade total da EB e os cálculos de EM, ELm e ELg foram feitos utilizando as seguintes fórmulas: $\mathrm{EM}=0,82 \mathrm{ED} ; \mathrm{ELm}=1,37 \mathrm{EM}-0,138 \mathrm{EM}^{2}$ $+0,0105 \mathrm{EM}^{3}-1,12$ e $\mathrm{ELg}=1,42 \mathrm{EM}-0,174 \mathrm{EM}^{2}$ $+0,01222 \mathrm{EM}^{3}-1,65$, obtidas a partir do NRC (1996).

A determinação do coeficiente de digestibilidade aparente ruminal dos nutrientes foi realizada a partir do ingerido, menos o fluxo duodenal, e o coeficiente de digestibilidade aparente total dos nutrientes foi calculado a partir da ingestão, menos o fluxo fecal, determinando, em ambos os casos, a porcentagem em relação ao ingerido, enquanto os cálculos de coeficientes de digestibilidade intestinal foram calculados com base no fluxo duodenal, menos o fluxo fecal, determinando-se posteriormente a porcentagem em relação ao fluxo duodenal.

Odelineamento experimental utilizado foi oquadrado latino 4 x 4, no qual foram avaliados quatro tratamentos. Os dados foram interpretados por uma análise de variância, adotando-se 5\% de probabilidade e utilizando-se o procedimento ANOVA do SAS (1989).

\section{Resultados e Discussão}

Os resultados referentes à ingestão, ao fluxo, digestão e coeficiente de digestibilidade da MS, MO e PB são mostrados na Tabela 2.

Com relação à MS, houve aumento $(\mathrm{P}<0,01)$ na ingestão, fluxo duodenal e fecal para a dieta com $70 \%$ de volumoso (Tabela 2). Considerando que foi mantida a ingestão de 1,3 vezes as exigências de ELm para todos os tratamentos e que a dieta AV apresentou concentração de ELm 15,7\% inferior, conclui-se 
GUIMARÃES et al.

Tabela 2 - Ingestão média diária (ING), fluxo duodenal (FD), fluxo fecal (FF), digestão ruminal (DR), digestão intestinal (DI), digestão total (DT), coeficiente de digestibilidade aparente ruminal (CDAR), coeficiente de digestibilidade aparente intestinal (CDAI) e coeficiente de digestibilidade aparente total (CDAT) da matéria seca (MS), matéria orgânica (MO) e proteína bruta (PB)

Table 2 - Average daily intake (INT), duodenal flow (DF), feaces flow (FF), ruminal digestion (RD), intestinal digestion (ID), total digestion (TD), coefficient of apparent ruminal digestibility (CARD), coefficient of apparent intestinal digestibility (CAID) and coefficient of apparent total digestibility (CATD) of dry matter (DM), organic matter (OM) and crude protein (CP)

\begin{tabular}{|c|c|c|c|c|c|}
\hline \multirow{3}{*}{$\begin{array}{l}\text { Item } \\
\text { Item }\end{array}$} & \multicolumn{4}{|c|}{$\begin{array}{c}\text { Efeito principal } \\
\text { Principal effect }\end{array}$} & \multirow[b]{3}{*}{$\begin{array}{l}\text { Erro-padrão da média } \\
\text { Standard error of the mean }\end{array}$} \\
\hline & \multicolumn{2}{|c|}{$\begin{array}{c}\text { Nível de volumoso, \% } \\
\text { Forage level, \% }\end{array}$} & \multicolumn{2}{|c|}{$\begin{array}{l}\text { Período experimental, dias } \\
\text { Experimental period, days }\end{array}$} & \\
\hline & 70 & 30 & 14 & 21 & \\
\hline & \multicolumn{4}{|c|}{ Matéria seca (Dry matter) } & \\
\hline $\begin{array}{l}\text { ING (g/dia) } \\
\text { INT (g/day) }\end{array}$ & 6670,92 & $5752,57 \cdots$ & 6244,64 & 6178,85 & 54,92 \\
\hline $\begin{array}{l}\mathrm{FD}(\mathrm{g} / \text { dia }) \\
D F(\text { g/day })\end{array}$ & 3791,11 & $3018,27^{* *}$ & 3435,15 & 3374,24 & 111,94 \\
\hline $\mathrm{FF}$ (g/dia) & 2288,95 & $1475,86^{* *}$ & 1868,88 & 1895,93 & 34,49 \\
\hline $\begin{array}{l}\mathrm{DR}(\mathrm{g} / \mathrm{dia}) \\
R D(\text { g/day })\end{array}$ & 2879,81 & 2734,30 & 2809,49 & 2804,61 & 118,34 \\
\hline $\begin{array}{l}\mathrm{DI}(\mathrm{g} / \text { dia }) \\
I D(\text { g/day })\end{array}$ & 1502,16 & 1542,41 & 1566,26 & 1478,31 & 109,00 \\
\hline $\begin{array}{l}\text { DT (g/dia) } \\
T D(g / \text { day })\end{array}$ & 4381,97 & 4276,71 & 4375,76 & 4282,92 & 69,45 \\
\hline $\begin{array}{l}\operatorname{CDAR}(\%) \\
C A R D\end{array}$ & 43,17 & 47,53 & 45,00 & 45,39 & 1,97 \\
\hline $\begin{array}{l}\text { CDAI }(\%) \\
C A I D\end{array}$ & 39,62 & $51,10^{* *}$ & 45,60 & 43,81 & 1,88 \\
\hline $\begin{array}{l}\operatorname{CDAT}(\%) \\
\text { CATD }\end{array}$ & 65,68 & $74,34^{* *}$ & 70,07 & 69,31 & 0,61 \\
\hline $\begin{array}{l}\text { ING (g/dia) } \\
\text { INT (g/day) }\end{array}$ & 6257,64 & $\begin{array}{l}\text { Maté } \\
5377,86^{* *}\end{array}$ & $\begin{array}{c}\text { ganic matt } \\
5853,42\end{array}$ & 5782,09 & 51,07 \\
\hline $\begin{array}{l}\mathrm{FD}(\mathrm{g} / \mathrm{dia}) \\
D F(\text { g/day })\end{array}$ & 2799,28 & $2396,62^{*}$ & 2635,35 & 2555,55 & 161,89 \\
\hline $\mathrm{FF}$ (g/dia) & 1987,78 & $1201,66^{* *}$ & 1578,47 & 1610,97 & 25,27 \\
\hline DR (g/dia) & 3464,36 & $2980,24^{*}$ & 3218,07 & 3226,53 & 183,81 \\
\hline$R D($ g/day $)$ & & & & & \\
\hline $\begin{array}{l}\mathrm{DI}(\mathrm{g} / \text { dia }) \\
\text { ID (g/day) }\end{array}$ & 805,90 & 1195,95 & 1056,87 & 944,58 & 172,61 \\
\hline $\begin{array}{l}\mathrm{DT} \text { (g/dia) } \\
T D \text { (g/day) }\end{array}$ & 4269,86 & 4176,19 & 4274,94 & 4171,12 & 50,61 \\
\hline $\begin{array}{l}\operatorname{CDAR}(\%) \\
\text { CARD }\end{array}$ & 55,41 & 55,11 & 54,67 & 55,85 & 2,99 \\
\hline $\begin{array}{l}\text { CDAI }(\%) \\
C A I D\end{array}$ & 27,48 & $48,57^{* *}$ & 38,83 & 37,63 & 4,65 \\
\hline $\begin{array}{l}\operatorname{CDAT}(\%) \\
\text { CATD }\end{array}$ & 68,22 & $77,63^{* *}$ & 73,35 & 72,50 & 0,41 \\
\hline $\begin{array}{l}\text { ING (g/dia) } \\
\text { INT (g/day) }\end{array}$ & 1042,33 & $\begin{array}{r}\text { Pro } \\
978,81^{* *}\end{array}$ & $\begin{array}{c}\text { de protein } \\
1022,33\end{array}$ & 998,81 & 7,04 \\
\hline $\begin{array}{l}\mathrm{FD}(\mathrm{g} / \mathrm{dia}) \\
D F(\text { g/day })\end{array}$ & 779,44 & 727,23 & 753,95 & 752,71 & 29,32 \\
\hline $\mathrm{FF}(\mathrm{g} / \mathrm{dia})$ & 255,50 & $202,83^{* *}$ & 227,92 & 230,41 & 4,47 \\
\hline $\begin{array}{l}\mathrm{DR}(\mathrm{g} / \mathrm{dia}) \\
R D(\text { g/dav })\end{array}$ & 262,89 & 251,58 & 268,37 & 246,10 & 29,36 \\
\hline $\begin{array}{l}\mathrm{DI} \text { (g/dia) } \\
I D \text { (g/day) }\end{array}$ & 523,94 & 524,40 & 526,04 & 522,30 & 30,25 \\
\hline $\begin{array}{l}\mathrm{DT} \text { (g/dia) } \\
T D \text { (g/day) }\end{array}$ & 786,83 & 775,98 & 794,41 & 768,40 & 10,70 \\
\hline $\begin{array}{l}\operatorname{CDAR}(\%) \\
\text { CARD }\end{array}$ & 25,22 & 25,70 & 26,25 & 24,64 & 2,88 \\
\hline $\begin{array}{l}\operatorname{CDAI}(\%) \\
C A I D\end{array}$ & 67,22 & $72,10^{*}$ & 69,77 & 69,39 & 1,38 \\
\hline $\begin{array}{l}\text { CDAT }(\%) \\
\text { CATD }\end{array}$ & 75,48 & $79,27^{* *}$ & 77,70 & 76,93 & 0,53 \\
\hline
\end{tabular}

${ }^{*} \mathrm{e}^{* *}$ significativo a 5 e $1 \%$ respectivamente (significant at 5 and $1 \%$, respectively). 
892 Rev. bras. zootec.

que este resultado foi coerente. Não houve efeito significativo dos níveis de volumosos para a digestão ruminal, intestinal e total $(\mathrm{g} / \mathrm{dia})$. Os dois níveis de volumosos não influenciaram $(\mathrm{P}>0,05)$ o coeficiente de digestibilidade ruminal, o que também ocorreu em experimentos realizados com bovinos por CARVALHO et al. (1997b), TIBO et al. (1997) e LADEIRA et al. (1999).

Os coeficientes de digestibilidade intestinal e total da MS foram maiores $(\mathrm{P}<0,01)$ na dieta com menor nível de volumoso (30\%), o que, segundo LADEIRA et al. (1999), pode ser explicado pela maior quantidade de carboidratos não estruturais (CNE) presentes nas dietas com maiores níveis de concentrado.

OSPINA e PRATES (1998), ao avaliarem níveis de oferta de feno para bovinos, verificaram que a digestibilidade total de todas as frações nutritivas foram influenciadas pelo nível de consumo de feno (volumoso), sendo que aumentos no consumo, invariavelmente, conduziram à queda na digestibilidade.

Ao analisar a interação período experimental dentro dos níveis de volumosos e o período experimental (Tabela 2), observa-se que não houve efeito significativo $(\mathrm{P}>0,05)$ para todos os parâmetros, avaliados em relação à MS. Os valores obtidos para coeficiente de digestibilidade total, nos diferentes períodos experimentais (Tabela 2), foram semelhantes aos apresentados por LADEIRA et al. (1999), que variaram de 66,0 a $77,2 \%$, porém, os valores de digestibilidade ruminal mostraram-se menores que os encontrados pelos mesmos autores, que variaram de 58,1 a $67,1 \%$, com um período experimental de 14 dias.

CARVALHO et al. (1997a) e RODRIGUEZ et al. (1997), avaliando diferentes níveis de volumoso, 30 a $80 \%$ e 50 a $87,5 \%$, respectivamente, em dietas de bovinos e utilizando período experimental com duração de 20 e 25 dias, respectivamente, obtiveram valores de coeficientes de digestibilidade total de MS entre 55,4 e $63,8 \%$ e entre 53,9 e $61,4 \%$. CECAVA et al. (1991) e LADEIRA et al. (1999), trabalhando com períodos experimentais de 16 e 14 dias e utilizando níveis de volumosos, variando de 32 a $82 \%$ e 25 a $75 \%$, respectivamente, obtiveram valores maiores para o coeficiente de digestibilidade total da MS, que variaram de 73,2 a $84,4 \%$ e 68,7 a $77,2 \%$, respectivamente.

Quanto à MO, observou-se comportamento semelhante à MS. Verificou-se diferença significativa para a ingestão $(\mathrm{P}<0,01)$, fluxo duodenal $(\mathrm{P}<0,05) \mathrm{e}$ fluxo fecal $(\mathrm{P}<0,01)$, sendo que os maiores valores ocorreram para a dieta com $70 \%$ de volumoso (Tabela 2 ).
A digestão intestinal e total (g/dia) e o coeficiente de digestibilidade ruminal (\%) não apresentaram diferença significativa $(\mathrm{P}>0,05)$ para o nível de volumoso. A digestão ruminal (g/dia) foi maior $(\mathrm{P}<0,05)$ para a dieta com $70 \%$ de volumoso e os coeficientes de digestibilidade intestinal $(\mathrm{P}<0,05)$ e total $(\mathrm{P}<0,01)$ foram maiores para a dieta com menor nível de volumoso (30\%).

A digestibilidade total da MO apresentou valores entre 68,4 e $77,9 \%$, superiores aos encontrados por ARAÚJO et al. (1998), 55,0 a 74,1\%, que utilizaram níveis de volumosos, variando de 10 a $90 \%$. Os maiores coeficientes de digestibilidade total da MO foram obtidos com a ração contendo menor porcentagem de volumoso e estão de acordo com os resultados obtidos por BOURQUIN et al (1994) e HUSSEIN et al. (1995).

A interação período experimental nos dois níveis de volumosos e o período experimental (Tabela 2) não afetou $(\mathrm{P}>0,05)$ os parâmetros avaliados para a MO.

Considerando níveis semelhantes de volumosos na dietas de bovinos, o coeficiente de digestibilidade total da MO foi menor nos trabalhos realizados por CARVALHO et al. (1997a) e RODRIGUEZ et al. (1997), que utilizaram períodos experimentais de $20 \mathrm{e}$ 25 dias e variaram de 55,4 a $63,8 \%$ e de 56,1 a $62,9 \%$, respectivamente, em comparação a outros autores como CECAVA et al. (1991), LADEIRA et al. (1999) e SIGNORETTI et al. (1999), que, utilizando períodos experimentais menores, obtiveram valores maiores que foram de 67,5 a $71,7 \%$; 70,6 a 78,7\%; e 71,9 a $80,9 \%$, respectivamente.

Em relação à $\mathrm{PB}$, os resultados obtidos quanto à ingestão, fluxo, digestão e coeficiente de digestibilidade são mostrados na Tabela 2. A dieta com menor nível de volumoso (30\%) apresentou menor $(\mathrm{P}<0,01)$ ingestão e fluxo fecal de PB. Não houve efeito $(\mathrm{P}>0,05)$ do nível de volumoso na dieta sobre a digestão ruminal, intestinal e total ( $\mathrm{g} / \mathrm{dia}$ ).

$O$ coeficiente de digestibilidade ruminal da PB não sofreu efeito $(\mathrm{P}>0,05)$ do nível de volumoso. Este comportamento também foi observado por CARVALHO et al. (1997b).

O coeficiente da digestibilidade intestinal da PB foi maior $(\mathrm{P}<0,05)$ para a dieta com $30 \%$ de volumoso, apesar do maior consumo de PB observado para a dieta com $70 \%$ de volumoso, o que leva a concluir que a PB proveniente da dieta com $70 \%$ de volumoso foi menos disponível no intestino, discordando dos resultados observados por BOURQUIN et al. (1994) e CARVALHO et al. (1997b), os quais 
verificaram que o coeficiente da digestibilidade intestinal da PB não sofreu efeito do nível de volumoso, ressaltando, porém, que os autores utilizaram o Orchardgrass (Dactylis glomerata) e o capim-elefante (Penissetum purpureum, Schum) como fonte de volumoso.

$O$ coeficiente de digestibilidade total da PB foi maior $(\mathrm{P}<0,01)$ para a dieta com $30 \%$ de volumoso, concordando com os resultados obtidos por SIGNORETTI et al. (1999), que observaram decréscimo linear do coeficiente de digestibilidade total da PB, com o aumento do nível de inclusão de volumoso.

Não houve efeito $(\mathrm{P}>0,05)$ do período experimental em cada nível de volumoso avaliado e do período experimental (Tabela 2) para os parâmetros de PB. Os valores de digestibilidade total da PB obtidos neste experimento, quando se considerou período experimental nos níveis de volumosos avaliados, variaram de 75,0 a 79,6\% e foram próximos aos encontrados por SIGNORETTI et al. (1999), que utilizaram um período experimental de 16 dias e níveis de volumosos, variando de 10 a $55 \%$, e foram maiores que os valores encontrados por CARVALHO et al (1997a), que utilizaram um período experimental de 20 dias e níveis de volumosos variando de 30 a $80 \%$.

CARVALHO et al. (1997a) e RODRIGUEZ et al. (1997), utilizando período experimental de 20 e 25 dias, obtiveram coeficiente de digestiblidade total da PB variando de 63,3 a 65,3\% e 63,9 a 67,9\%, respectivamente. Estes valores são próximos (50,7 a 68,3\%) aos encontrados por ARAÚJO et al. (1998) e menores $(72,8$ a $78,1 \%)$ que os encontrados por SIGNORETTI et al. (1999), que utilizaram período experimental de 16 dias.

Constam da Tabela 3 os resultados obtidos para FDA e FDN, os quais apresentaram comportamento semelhante. A ingestão, o fluxo duodenal e o fluxo fecal de FDA e FDN foram maiores $(\mathrm{P}<0,01)$ para a dieta com $70 \%$ de volumoso.

A digestão ruminal (g/dia) de FDA e FDN aumentou $(\mathrm{P}<0,01)$ com o maior nível de forragem $(70 \%)$, mostrando que a utilização da fibra a nível ruminal é dependente do nível de volumoso na dieta. A digestão intestinal não foi influenciada $(\mathrm{P}>0,05)$ pelo nível de volumoso. A digestão total de FDA e FDN mostrou o mesmo comportamento que a digestão ruminal, aumentando $(\mathrm{P}<0,01)$, com a dieta contendo $70 \%$ de forragem.

O coeficiente de digestibilidade ruminal de FDA e FDN diminuiu $(\mathrm{P}<0,05)$, à medida que se reduziu o nível de volumoso na dieta, o que, de acordo com
LADEIRA et al. (1999), pode ser explicado pelo fato de a utilização de níveis elevados de concentrado reduzir o $\mathrm{pH}$ e, conseqüentemente, a digestão ruminal de carboidratos da parede celular. Não houve efeito ( $P>0,05)$ do nível de volumoso sobre o coeficiente de digestibilidade intestinal e total para FDA e FDN.

POORE et al (1990) não encontraram diferenças significativas para a digestibilidade ruminal de FDN, quando se utilizaram níveis de concentrado de 30 e $60 \%$ nas dietas de bovinos, porém observaram redução na digestibilidade ruminal, quando utilizaram $90 \%$ de concentrado na dieta.

BERCHIELLI et al. (1994) verificaram que a digestibilidade ruminal, intestinal e total da FDN não foi influenciada pelos níveis de volumosos. HUSSEIN et al. (1995), RODRIGUEZ et al. (1997) e SIGNORETTI et al. (1999) observaram comportamento semelhante quanto à digestibilidade total de FDN e CARVALHO et al. (1997a), o mesmo comportamento para FDA e FDN.

Avaliando a interação período experimental nos dois níveis de volumosos e o período experimental (Tabela 3), observou-se que não houve efeito significativo $(\mathrm{P}>0,05)$ para todos os parâmetros avaliados com relação à FDA e FDN.

CARVALHO et al. (1997b) e LADEIRA et al. (1999) obtiveram coeficientes de digestibilidade ruminal de FDN semelhantes, embora tenham utilizados períodos experimentais diferentes. Entretanto, os valores obtidos por CECAVA et al. (1991) foram inferiores aos encontrados por LADEIRA et al. (1999), que utilizaram período experimental semelhante.

Ao se avaliar o amido (Tabela 3 ), observou-se ingestão superior $(\mathrm{P}<0,01)$ para dieta com menor nível de volumoso (30\%), enquanto com os fluxos duodenal e fecal isto não ocorreu, mostrando que a maior parte do amido foi digerida no rúmen, independentemente da dieta.

A digestão ruminal e total do amido (g/dia) aumentou $(\mathrm{P}<0,01)$ com a redução do nível de volumoso, todavia, com a digestão intestinal, isto, provavelmente, não ocorreu porque a passagem de amido para o intestino foi baixa.

O coeficiente da digestibilidade ruminal do amido não sofreu efeito $(\mathrm{P}>0,05)$ do nível de volumoso, mas os coeficientes de digestibilidade intestinal $(\mathrm{P}<0,01)$ e total $(\mathrm{P}<0,01)$ foram os maiores para a dieta com $30 \%$ de volumoso. BERCHIELLI et al. (1994), avaliando níveis crescentes de concentrado na dieta, observaram que a digestibilidade ruminal, intestinal e total do amido não foi afetada com o aumento do nível de inclusão. 
894 Rev. bras. zootec.

Tabela 3 - Ingestão média diária (ING), fluxo duodenal (FD), fluxo fecal (FF), digestão ruminal (DR), digestão intestinal (DI), digestão total (DT), coeficiente de digestibilidade aparente ruminal (CDAR), coeficiente de digestibilidade aparente intestinal (CDAl) e coeficiente de digestibilidade aparente total (CDAT) da fibra em detergente ácido (FDA), fibra em detergente neutro (FDN) e amido

Table 3 - Average daily intake (INT), duodenal flow (DF), feaces flow (FF), ruminal digestion (RD), intestinal digestion (ID), total digestion (TD), coefficient of apparent ruminal digestibility (CARD), coefficient of apparent intestinal digestibility (CAID) and coefficient of apparent total digestibility (CATD) of acid detergent fiber (ADF), neutral detergent fiber (NDF) and starch

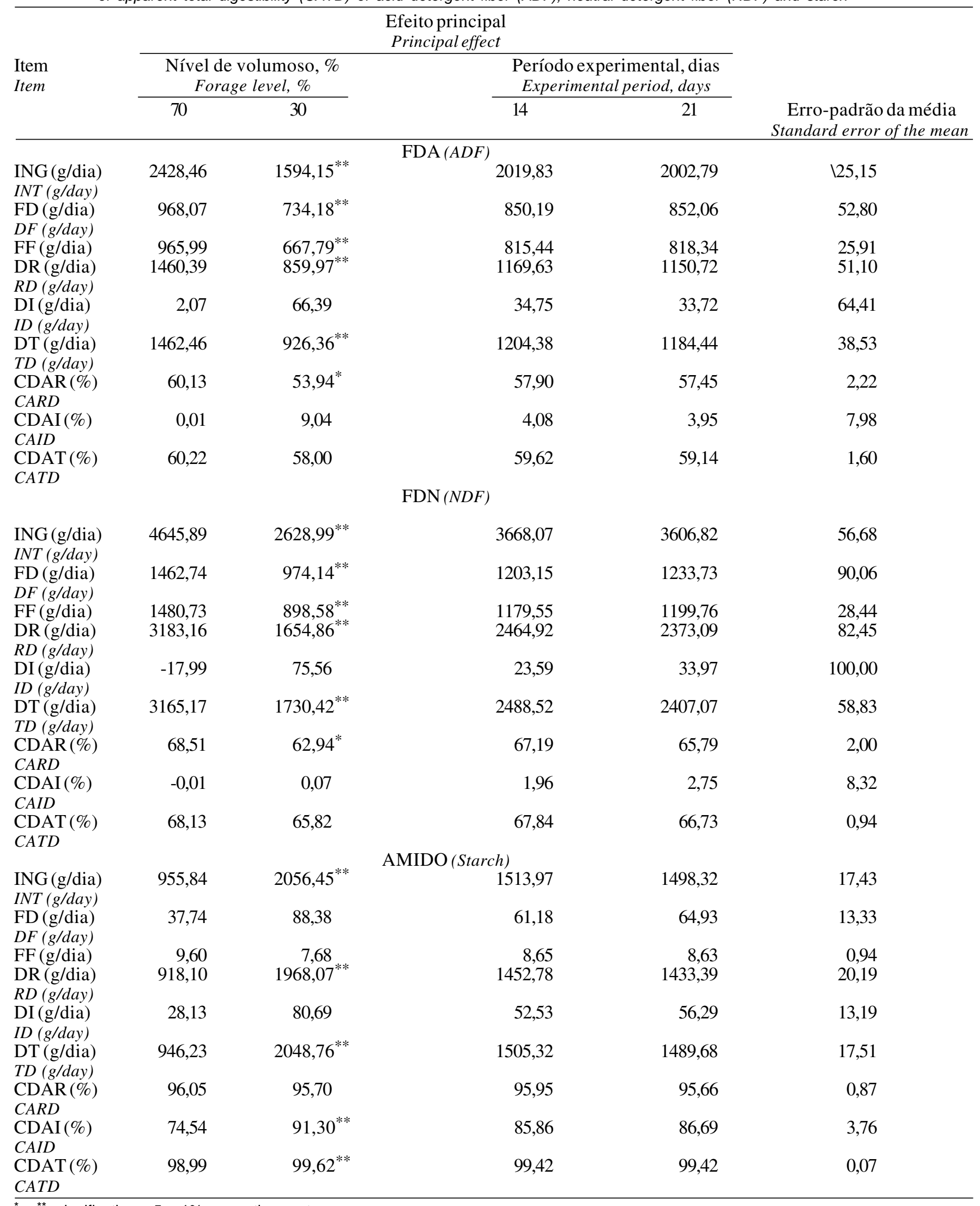

\footnotetext{
${ }^{*} \mathrm{e}^{\star *}$ significativo a 5 e $1 \%$ respectivamente (significant at 5 and $1 \%$, respectively).
} 
GUIMARÃES et al.

Para todos os parâmetros avaliados em relação ao amido, não houve efeito $(\mathrm{P}>0,05)$ do período experimental e da interação do período experimental com os níveis de volumosos avaliados.

$\mathrm{Na}$ avaliação da energia (Tabela 4), verificou-se o efeito do nível de volumoso $(\mathrm{P}<0,01)$ para todos os parâmetros avaliados. O coeficiente de digestibilidade total da energia bruta aumentou com a redução do volumoso, comportamento também observado por HUSSEIN et al (1995) e SIGNORETTI et al. (1999).

Os demais parâmetros, como a concentração de ED, EM, ELm e ELg da dieta, também aumentaram com a redução do teor de volumoso.

O período experimental nos diferentes níveis de volumoso e o período experimental (Tabela 4) não afetaram $(\mathrm{P}>0,05)$ os parâmetros avaliados para a energia.

Os valores obtidos para o coeficiente de digestibilidade total de energia bruta variaram de
63,9 a $74,3 \%$ e, quando se considerou a interação período experimental nos dois níveis de volumoso, estes valores estiveram próximos aos encontrados por ARAÚJO et al. (1998), que avaliaram diferentes níveis de volumosos (10 a 90\%), usando feno de Coastcross (Cynodon dactylon) e período experimental de 16 dias.

\section{Conclusões}

Não houve interação entre o período experimental (14 e 21 dias) e nível de volumoso (30 e 70\%) na dieta para todos os parâmetros estudados. Não houve efeito do período experimental para todos os parâmetros avaliados, o que permite concluir que 14 dias são suficientes para a completa adaptação dos animais às dietas e, portanto, períodos experimentais com essa duração são viáveis, quando se usa o feno como fonte de volumoso.

Tabela 4 - Ingestão média diária (ING), excreção fecal (EXC), coeficiente de digestibilidade aparente total (CDAT) da energia bruta (EB) e valores de energia digestível (ED), energia metabolizável (EM), energia líquida de mantença (ELm) e energia líquida de ganho (ELg)

Table 4 - Average daily intake (INT), fecal flow (FF), coefficient of apparent total digestibility (CATD) of gross energy (GE), and values of digestible energy $(D E)$, metabolizable energy (ME), net energy for maintenance (NEm) and net energy for gain (NEg)

\begin{tabular}{|c|c|c|c|c|c|}
\hline \multirow{3}{*}{$\begin{array}{l}\text { Item } \\
\text { Item }\end{array}$} & \multicolumn{4}{|c|}{$\begin{array}{c}\text { Efeito principal } \\
\text { Principal effect }\end{array}$} & \multirow[b]{3}{*}{$\begin{array}{l}\text { Erro padrão } \\
\text { da média } \\
\text { Standard error } \\
\text { of the mean }\end{array}$} \\
\hline & \multicolumn{2}{|c|}{$\begin{array}{l}\text { Nível de volumoso, \% } \\
\text { Forage level, \% }\end{array}$} & \multicolumn{2}{|c|}{$\begin{array}{l}\text { Período experimental, dias } \\
\text { Experimental period, days }\end{array}$} & \\
\hline & 70 & 30 & 14 & 21 & \\
\hline $\begin{array}{l}\text { ING (Mcal/dia) } \\
\text { INT (g/day) }\end{array}$ & 28,93 & $24,39^{* *}$ & 26,74 & 26,57 & 2,94 \\
\hline $\begin{array}{l}\text { EXC }(\text { Mcal/dia }) \\
\text { EXC }(\text { Mcal/dav })\end{array}$ & 10,36 & $6,27^{* *}$ & 8,31 & 8,31 & 1,37 \\
\hline $\begin{array}{l}\text { CDAT }(\%) \\
\text { CATD }\end{array}$ & 64,20 & $74,27^{* *}$ & 68,91 & 68,70 & 0,39 \\
\hline $\begin{array}{l}\mathrm{ED}(\mathrm{Mcal} / \mathrm{kg} \text { de } \mathrm{MS}) \\
D E(\text { Mcal/kg DM) }\end{array}$ & 2,78 & $3,15^{* *}$ & 2,96 & 2,97 & 0,02 \\
\hline $\begin{array}{l}\mathrm{EM}(\mathrm{Mcal} / \mathrm{kg} \text { de MS }) \\
M E(\text { Mcal/kg DM) }\end{array}$ & 2,28 & $2,58^{* *}$ & 2,43 & 2,43 & 0,02 \\
\hline $\begin{array}{l}\text { ELm (Mcal/kg de MS) } \\
N E m(\text { Mcal/kg DM) }\end{array}$ & 1,41 & $1,68^{* *}$ & 1,54 & 1,54 & 0,01 \\
\hline $\begin{array}{l}\text { ELg (Mcal/kg de MS) } \\
N E g(\text { Mcal/kg DM) }\end{array}$ & 0,83 & $1,07^{* *}$ & 0,94 & 0,94 & 0,01 \\
\hline
\end{tabular}

${ }^{* \star}$ significativo a $1 \%$ (significant at $\left.1 \%\right)$. 


\section{Referências Bibliográficas}

ARAÚJO, G.G.L., COELHO DA SILVA, J.F., VALADARES FILHO, S.C. et al. 1998. Consumo e digestibilidade total dos nutrientes de dietas contendo diferentes níveis de volumoso em bezerros. R. Bras. Zootec., 27(2):345-354.

BERCHIELLI, T.T., RODRIGUEZ, N.M., OLIVEIRA, H.P. et al. Ingestão, digestibilidade aparente total e partição da digestão em função dos níveis crescentes de concentrado na dieta. In: REUNIÃO ANUAL DA SOCIEDADE BRASILEIRA DE ZOOTECNIA, 31, 1994, Maringá. Anais...Maringá: SBZ, 1994. p.489.

BOURQUIN, L.D., TITGEMEYER, E.C., MERCHEN, N.R. et al. 1994. Forage level and particle size effects on Orchardgrass digestion by steers. Site and extent of organic matter, nitrogen and cell wall digestion. J. Anim. Sci., 72:746-758.

CARVALHO, A.V., VALADARES FILHO, S.C., COELHO DA SILVA, J.F. et al. 1997a. Níveis de concentrado em dietas de zebuínos. Consumo e digestibilidade aparente. R. Bras. Zootec., 26(5):986-995.

CARVALHO, A.V., VALADARES FILHO, S.C., COELHO DA SILVA, J.F. et al. 1997b. Níveis de concentrado em dietas de zebuínos. Coeficientes de digestibilidades aparentes parciais. R. Bras. Zootec., 26(5):996-1006.

CECAVA, M.J., MERCHEN, N.R., GAY L.C. 1991. Composition of ruminal bacteria harvested from steers as influenced by dietary energy level, feeding frequency and isolation techniques. J. Dairy Sci., 73(9): 2480-2488.

EZEQUIEL, J.M.B., SAMPAIO, A.A.M., OLIVEIRA, M.D.S. 1995. Efeito do período de coleta sobre a digestibilidade de alguns nutrientes, em ensaios com ovinos. R. Soc. Bras. Zootec., 24(2):261-269.

HUSSEIN, H.S., MERCHEN, N.R., FAHEY G.C.J. 1995. Effects of forage level and canola seed supplementation on site and extent of digestion of organic matter, carbohydrates and enegy by steers. J. Anim. Sci., 73:2458-2468.

LADEIRA, M.M., VALADARES FILHO, S.C., COELHO DA SILVA, J.F. et al. 1999. Consumo e digestibilidades aparentes totais e parciais de dietas contendo diferentes níveis de concentrado, em novilhos nelore. Rev. bras. zootec., 28(2):395-403.

MERCHEN, N.R. 1988. Digestion, absorption and excretion in ruminants. In: CHURCH, D.C. (Ed.) The ruminant animal: digestive physiology and nutrition. Prentice hall: Englewood cliffs. 2.ed. p.172-201.

NATIONAL RESEARCH COUNCIL - NRC. 1996. Nutrient requeriment of beef cattle. 7.ed. Washington D.C. 242p.

OSPINA, H., PRATES, E.R. 1998. Efeito de quatro níveis de oferta de feno sobre o consumo de nutrientes digestíveis por bezerros. R. Bras. Zootec., 27(4): 809-814.
PEREIRA, J.R.A, ROSSI, P. 1995. Manual prático de avaliação nutricional de alimentos. Piracicaba: FEALQ. 25p.

POORE, M.H., MOORE, J.A., SWINGLE R.S. 1990. Diferencial passage rates and digestion of neutral detergent fiber from grain and forage in 30,60 and 90\% concentrate diets fed to steers. J. Anim. Sci., 68(9):2965-2973.

RODRIGUEZ, L.R.R., FONTES, C.A.A., JORGE, A.M. et al. 1997. Digestibilidade de rações contendo quatro níveis de concentrado em bovinos (taurinos e zebuinos) e bubalinos. R. Bras. Zootec., 26(4): 844-851.

SAS INSTITUTE INC., SAS/STAT. 1989. Version 6, 4.ed., Cary, NC: SAS institute Inc., 943p. (User's guide)

SIGNORETTI, R.D., COELHO DA SLVA, J.F., VALADARES FILHO, S.C. et al. 1999. Consumo e digestibilidade aparente em bezerros da raça holandesa alimentados com dietas, contendo diferentes níveis de volumoso. Rev. Bras. Zootec. 28(1):169-177.

SILVA, D.J. 1990. Análise de alimentos(métodos químicos e biológicos). 2.ed. Viçosa: UFV. 166p.

THEURER, B., RAHNEMA, S., GARCIA, J.A et al. 1981. Effect of 2- versus 6- day collections for the determination of ruminal and post ruminal digestion in steers. J. Anim. Sci., 52(1):134-137.

TIBO, G.C., VALADARES FILHO, S.C., COELHO da SILVA, J.F. et al. Consumo, digestibilidades e metodologias de coleta de amostras de digesta em novilhos alimentados com vários níveis de concentrado. In: REUNIÃO ANUAL DA SOCIEDADE BRASILEIRA DE ZOOTECNIA, 34, 1997, Juiz de Fora. Anais... Juiz de fora: SBZ, 1997. p.188-219.

TITGEMEYER, E.C. 1997. Design and interpretation of nutrient digestion studies. J. Anim. Sci., 75:2235-2247.

VAN SOEST, P.J. 1994. Nutritional ecology of the ruminant. 2.ed. London: Cornell University. 476p.

WILLIAMS, C.H., DAVID, D.J., ILSMAA, O. 1962. The determination chromic oxide in faeces samples by atomic absorption spectrophotometry. J. Anim. Sci., 59(1): 391.

Recebido em: 29/05/00 Aceito em: 30/03/01 